\title{
Determination by the Settlement Systems of the Required Collateral Imposed to Participants
}

\author{
Laurentiu Paul BARANGA \\ Bucharest University of Economic Studies, Bucharest, Romania \\ barangalp@yahoo.com \\ Iulian ZALINCA \\ Bucharest University of Economic Studies, Bucharest, Romania \\ zalinca@gmail.com
}

\begin{abstract}
The dynamics of the increase in volume and amount of the financial or commercial transactions during the last decennials has amplified the role of clearing and settlement systems, along with the payment ones. From the quality of these systems as a financial markets stability provider also derives the concern for the management of financial risks mainly generated by the participants in these systems. The clearingsettlement systems, operated by infrastructure entities of the capital markets, ensure, within certain limits, a risk management for the incidents that could occur in the settlement activity regarding the financial transactions concluded between participants. We are going to present a methodology for determining the required collateral that must be maintained/updated by the debtor participants of a clearing-settlement system in order to ensure a robust management of the risks that could occur in the settlement operations. This methodology can be applied by any infrastructure entity of the capital market that manages collateral systems to limit the number of cases of settlement fails in financial transactions.
\end{abstract}

Keywords: Collateral System, Settlement Operations, Securities Settlement System, Participants.

\section{Introduction}

The main purpose of a securities settlement system (or SSS) is to ensure that sellers and buyers receive their money and securities on time and without risks. This purpose is easy to achieve under ideal conditions; however, on the financial markets, certain events or evolutions occur that impose some risk management measures to be taken, as well as settlement discipline measures.

In the current activity, the securities settlement systems must prevalently manage the risks associated to the custody of financial instruments and to the settlement of transactions involving these, particularly the liquidity risk, the credit risk, and the operational risk. The liquidity risk and the credit risk are generated by the financial transactions concluded by the participants, whereas the operational risk occurs as a result of the custody activity or of the operations carried out by the securities transactions settlement systems.

The exposure to the liquidity risk takes into account the potential losses caused by the situation where a counterparty (participant or some other entity) does not have sufficient funds/securities on maturity to fulfil its obligations, although it could be able to do this in the future.

The exposure to the credit risk takes into account the potential losses caused by the situation where a counterparty (participant or some other entity) is unable to fulfil its financial obligations undertaken when concluding the financial transactions. Thus, the exposure to the credit risk consists of two sub-categories, namely: the exposure to the risk attached to the replacement cost (where the potential loss is represented by the volatility of the price of the asset between the original transaction date and the redone transaction date) and the exposure to the main risk (associated with the settlement risk of the price/financial asset contemplated by the transaction). 
The risk attached to the replacement cost is the risk of losing unrealized gain from the unsettled transactions with a counterparty. The exposure relevant to this risk is the replacement cost of the original transaction that became unable to make payments at the current market quotations. The main risk is the risk that a counterparty loses the entire amount involved in a transaction.

The losses caused by the operational risk contemplate the deficiencies of the computer

PICBE | 926 systems or of the internal processes, the human errors and the management fails due to external events affecting the provided services.

In the risk management activity, the security settlement systems have a series of instruments, such as: the credit and liquidity risk management mechanisms (daily trading limits imposed to each participant; financing arrangements or special/redone transactions; orderly restructuring of operations) and the collaterals provided by the participant in the settlement system.

The collaterals provided at the SSS level are used to limit the losses and pressures on liquidity, generated by the insolvency of one or more of the participants. The collateral system is organized in two components, i.e.: a collective guarantee fund and a margin system.

The guarantee fund consists of the fixed (original) ${ }^{1}$ contribution and of additional (subsequent) contributions provided by the participants. The margin system ${ }^{2}$ of the participants consists of the original margins and the additional margins ${ }^{3}$ charged to each participant. The additional margin is charged for certain time intervals, depending on the evolution of the market and on the activity of participants.

The margins are used with priority in the event of a lack of funds in the settlement account of the clearing participant/payment agent with whom it entered into a contract, or after using the Guarantee Fund, if there is a lack of funds in the settlement account of another Participant's funds.

If the provided collaterals fail to fully cover the participant's debt position, the SSS will recalculate the net debt position by excluding a number of transactions from the net basis settlement, so that the new net debt position may be fully covered by the provided collateral.

The main mechanism for managing the risks associated to the settlement operations is to limit the net exposure amount resulting from the concluded transactions (https://www.roclear.ro/Download?ID=5094\&Lang=en-US). The purpose of this limit is to limit the exposure to the risk of not paying the obligations deriving from the transactions concluded in the systems of that particular trading venue, during a trading session and recorded in the clearingsettlement system.

If, to complete the settlement of sale/purchase transactions, the funds/financial instruments of the participant are no enough, one can resort to the following operations: obtaining a loan; special sale transactions (special sell-out); transaction remaking operations; sale transactions concluded outside the trading systems, conducted in view of obtaining funds/financial instruments.

\section{Literature review}

The specialized literature does not include any approaches of the subject of determining the required collateral that must be maintained by the participants in an SSS. Such methods of determining the collateral system can be found in the internal regulations of the entities operating the security settlement systems.

\footnotetext{
${ }^{1}$ Acceptance in the settlement system is conditional on paying the fixed (original) contribution

${ }^{2}$ The margin is a security deposit in the form of money or government securities

${ }^{3}$ Depending on the money deposited/withdrawn by the participant
} 
A paper by Laurențiu Paul Baranga as co-author has recently been published. They proposed a risk assessment framework used by the CCP in daily activity in order to determine the minimum collateral levels that participants must keep in the margin accounts. The proposal included a structure of indicators required for assessing the risks associated to the clearing and settlement of financial transactions and took into account all factors influencing the settlement operations, both positively and negatively, namely:

PICBE | 927

- the asset type, the risks associated to the financial instrument brought as collateral, as well as the residual risk that could result from an error in the econometric calculation for determining the collateral requirement;

- the impact a participant could experience in case of becoming unable to pay, the dynamics of this impact, as well as the participant's creditworthiness;

- the risk characteristics of the traded financial instrument, namely: volatility, market liquidity, implications of volatility on the risk management operations and their capacity to reduce the exposure/net debit position experienced by that particular participant, the procedure and forced closing periods,

the aggregated risk level of an asset brought as collateral, limitation of pro-cyclicality, avoidance of concentrations of collaterals, and capacity to reuse the collateral. At EU level, a series of regulations and recommendations have been issued, presenting the eligibility requirements to be met by the risk management systems used by capital markets infrastructure entities operating the clearing-settlement systems. Also, IOSCO issued recommendations and principles that must be taken into account by the clearing-settlement systems when they develop their risk management policies and systems.

\section{Methodology}

In the methodology for determining the required collateral that must be maintained/provided by participants, the requirements specified in the Guidelines/regulations issued by IOSCO/CESR \& European Central Bank/ESMA/EU were generally taken into account. To that effect, the following factors capable of affecting the settlement of securities transactions were taken into account, namely:

$\checkmark$ creditworthiness (solvency risk) of the participant in the securities settlement system;

$\checkmark$ ensuring the correspondence between the participant's creditworthiness and its contribution to the Guarantee Fund;

$\checkmark$ the impact the exposure of a participant in the settlement system could have in the event of becoming unable to make payments;

$\checkmark$ the dynamics of the impact a participant in the securities settlement system could have in the event of becoming unable to make payments;

$\checkmark$ the volatility of the market and its implications on the risk management operations in the settlement.

Thus, to determine the settlement limit, the starting point was the maximum capacity of a participant to cover any net debt position with the collateral provided within a very short time horizon and, at the same time, the settlement risk management operations and their effect on the participant's net debt position were taken into account. To determine the net debt position, the situation of the settlement of net basis settlement transactions was taken into account. 
As a result of the above, to determine a formula for calculating the requirement of collaterals to be provided for the SSS operator's collateral systems, the following stages were taken into account:

- stage 1 - determination of the required collateral that must be permanently maintained. These are updated on a regular basis and permanently maintained between two reassessment dates of the collateral.

PICBE | 928

- stage 2 - determination of the settlement limit of the transactions concluded by a participant depending on the level of collateral that must be permanently maintained.

- stage 3 - determination of the additional required collateral to be provided by the participant in order to cover the difference between the value of the net debt position and the value of the settlement limit.

- $\quad$ stage 4 - presentation of the formula regarding the additional required collateral.

In the first stage, the focus is on the collateral provided by the participant in the guarantee fund and in the margin system. Besides these, other aspects are also taken into account, such as: the participant's creditworthiness, ensuring a correspondence between the creditworthiness and the contribution of the participant to the guarantee fund, the impact the participant could have on the settlement system if it becomes unable to make payments, as well as the dynamics of such impact on the settlement system.

To cover all the aforementioned factors, the formula for determining the required collateral to be permanently maintained is the following:

where:

$$
R C P=C G F+C M S
$$

- $\mathrm{RCP}=$ required collateral to be permanently maintained by the participant in the collateral system;

- $\mathrm{CGF}=$ contributions brought/maintained regularly by the participant in the guarantee fund;

- $\mathrm{CMS}=$ contributions brought/maintained regularly by the participant in the margin accounts system.

In the second stage, the focus is on the market volatility and its implications on the risk management operations in settlement, as well as the on the collateral level to be permanently maintained. The impact of the replacement cost in the remaking of a transaction is given by the unfavourable difference recorded by the good faith party of the failed transaction between the market price of the security, established in the original transaction, and the market price established in the redone transaction. This market price difference depends on the volatility of the price of such security recorded between the two dates.

In order to limit the negative impact on the risk management operations in the settlement activity, a settlement limit must be established for each participant, depending on the collateral provided permanently and on the volatility of the securities contemplated by the transactions concluded by such participant.

To cover all the aforementioned factors, the formula for determining the settlement limit is the following:

where:

$$
V S L=M F * R C P
$$

- VSL $=$ the value of the settlement limit that can be ensured by the settlement system for transactions concluded by a participant;

- $\mathrm{MF}=$ the multiplication factor of the value of the collaterals that must be permanently maintained by a participant; 
- $\mathrm{RCP}=$ the value of the guarantees provided by a participant and which are permanently maintained.

The formula for determining the multiplication factor of the value of collaterals that must be maintained permanently by a participant is the following:

$$
M F=100 /(\operatorname{sigma} * S F)
$$

where:

PICBE $\mid 929$

- MF $=$ the multiplication factor of the value of collaterals that must be permanently maintained by a participant;

- Sigma $=$ the volatility of the indicator that is part of the security contemplated by the transactions concluded by a participant;

- $\mathrm{SF}=$ supplement factor taking into account the potential margins for errors. These margins for errors take into account the differences between the dynamics of the index value and the dynamics of the market price of the security due to the lower liquidity of that security as compared to the median of the liquidity level of the securities included in that stock index.

In the third stage, the focus is on the value of the net debt position resulting after the clearing and settlement of the transactions with settlement on the net basis within a short time horizon of the transactions concluded by the participant and the value of the settlement limit guaranteeing the full coverage of a certain level of the net debt position with the collaterals provided by the participant.

The potential differences between the value of the net debt position recorded by a participant and the value of the settlement limit are the value of the current additional required collateral that must be provided/deposited by the participant into the margin account so as to be able to settle all the transactions concluded during that particular trading session. Thus, the manager of the settlement system will perform a margin call to the participant whose value of the settlement limit is exceeded by the value of the net debt positions in order to supplement the margin account with current additional collateral.

If the participant fails to respond to the margin call, the operator of the settlement system will resort to orderly restructuring of the operations and, implicitly, to a recalculation of the net debt position by excluding a number of transactions from the net basic settlement, so that the new net debt position obtained may be fully covered by the collateral provided. The transactions that were not included in that settlement session will be reprioritized for the following settlement session.

In view of covering all the aforementioned factors, the formula for determining the current additional required collateral is the following:

where:

$$
V C A C=V N D P-V S L
$$

- $\quad \mathrm{VCAC}=$ the value of the current additional collateral that must be provided by the participant in order to settle all the transactions in the same settlement session;

- $\quad \mathrm{VNDP}=$ the value of the net debt position relevant to the transactions concluded by a participant in a trading session;

- VSL = the value of the settlement limit that can be ensured by the settlement system for transactions concluded by a participant.

In the fourth stage, as a result of the aggregation of the three stages mentioned above, the formula for determining the current additional required collateral may also be stated as follows:

$$
V C A C=V N D P-[M F *(C G F+C M S)]
$$


where:

- $\mathrm{VCAC}=$ the value of the current additional collateral that must be provided by the participant in order to settle all the transactions in the same settlement session;

- VNDP = the value of the net debt position relevant to the transactions concluded by a participant in a trading session;

- $\mathrm{MF}=$ the multiplication factor of the value of the collaterals that must be permanently

PICBE | 930 maintained by a participant;

- $\mathrm{CGF}=$ contributions brought/maintained regularly by the participant in the guarantee fund;

- $\mathrm{CMS}=$ contributions brought/maintained regularly by the participant in the margin accounts system.

At the same time, if we include in the formula for determining the current additional required collateral all the factors taken into account in calculating one of the components, the formula will look like this:

$$
V C A C=V N D P-\{[100 /(\operatorname{sigma} * S F)] *[P D *(N D P+S D N D P)]\}
$$

where:

- $\mathrm{VCAC}=$ the value of the current additional collateral that must be provided by the participant in order to settle all the transactions in the same settlement session;

- VNDP = the value of the net debt position relevant to the transactions concluded by a participant in a trading session;

- Sigma $=$ the volatility of the indicator that is part of the security contemplated by the transactions concluded by a participant;

- SF = supplement factor taking into account the potential margins for errors. These margins for errors take into account the differences between the dynamics of the index value and the dynamics of the market price of the security due to the lower liquidity of that security as compared to the median of the liquidity level of the securities included in that stock index.

- PD - the probability of default, determined depending on the participant's rating;

- NDP - the participant's usual net debt position, which is an average value of the net debt exposures recorded by the participant during the last 12 months and that the settlement system must manage;

- SDNDP - standard deviation of the net debt position, which takes into account the dynamics of the average value of the net debt exposures recorded by a participant during the last 12 months.

In the following, we are going to present in detail each component of the formula for determining the current additional required collaterals, the principles taken into account, the factors/indicators taken into account in determining the composition, the determination periodicity, as well as any other relevant aspect.

\section{Contributions to the guarantee system.}

The Guarantee Fund and the margin accounts are formed with a view to ensuring the financial resources needed for the proper operation of the settlement mechanism for transactions with net basis settlement recorded in the securities settlement system. The bookkeeping of the contributions deposited in the account of the Guarantee Fund and in the margin accounts system is kept separately for each Participant.

These contributions to the guarantee system are required collaterals that must be permanently maintained between two dates of recalculation/reassessment of the level of such 
collaterals constituted by the participant in the settlement system. The components of the participants' components to the guarantee system are the following:

a. Contribution to the Guarantee Fund - CGF.

The size of the contribution is related to the level of the internal rating ascribed to the participant as a result of the application, by the settlement system operator, of the creditworthiness assessment procedure. The internal rating is determined based on a scoring formula which takes into account both the indicators provided by the legislation on capital adequacy and economic and financial indicators.

For the assessment of the participants, the following aspects must be taken into account:

- the type of participant in the settlement system - separate assessment methodologies will be made for each category of participant (credit institutions, investment firms with fully authorized scope of business; investment firms with partly authorized scope of business);

- the concurrent qualities a participant may have - a financial entity may have the following set of concurrent qualities: participant in the settlement system and custodian agent. For each quality, the required collateral in the settlement system is calculated separately;

- prudential indicators provided by the applicable legislation on capital adequacy - to ensure a standardized data source for all participants;

- economic and financial indicators - in order to fulfil the information offered by the prudential indicators - these indicators also benefit from the standardized character imposed by the applicable legislation;

- potential impact a participant may have in the settlement system if it becomes unable to make payments - the focus is on the participant's exposure in the net basis settlement (the average daily value of the net debt positions recorded during the last 12 months). The potential impact is determined at the beginning of the ongoing semester as the average of the values recorded in the net basis settlement for the last 12 months.

The determination of the original CGF is made by applying one of the following variants/options: i) a certain percentage from the value of the minimum original capital or a unitary minimum lump sum for all the participants on entering the settlement system, ii) application of a lump sum depending on the exposure limit allowed by the settlement system for the relevant participant, iii) application of a percentage to the value of the participant's total assets, iv) as well as a combination between the latter two, where, besides the lump sum, a recalculation of this sum is applied depending on the dynamics of the recorded exposures.

In the following, we are going to present the CGF as a lump sum determined depending on the exposure limit allowed by the settlement system for that particular participant, which is regularly recalculated in order to also detect any potential problems susceptible to occur in the dynamics of the recorded exposures.

Subsequently, after determining the minimum level on entering the settlement system or after determining the lump sum depending on the allowed exposure limit, the size of the contribution to the Guarantee Fund is recalculated on a semi-annual basis. After recalculating the size of the contribution to the Guarantee Fund, the choice will be in favour of whichever is largest of: the size of the previous contribution (original, for newcomers) recorded in the settlement system and the size of the contribution after its reassessment/recalculation at the beginning of the semester.

The recalculation of the contribution to the Guarantee Fund is conducted based on the following formula:

where:

$$
C G F=P D * N D P
$$


- $\quad$ CGF - contribution to the Guarantee Fund (expressed in absolute value);

- $\quad$ PD - probability of default, determined depending on the participant's rating (expressed as a percentage value);

- NDP - the indicator that takes into account the usual value of the debt exposure of a participant and is calculated as the average of the net debt positions recorded by the relevant participant during the last 12 months (expressed in absolute value).

PICBE | 932

The formula for determining the contribution to the Guarantee Fund takes into account the formula for determining the expected loss if a credit risk gets materialized. This principle was chosen because the replacement cost is a component of the credit risk attached to the settlement operations for securities transactions. The formula for calculating the expected loss is the following:

where:

$$
\text { “EL }=P D * L G D * E A D " 4
$$

- $\quad$ EL - expected loss by the creditor (expressed in absolute value);

- PD - debtor's probability of default (expressed as a percentage value);

- LGD - debtor's loss given default that could be experienced by the creditor (expressed as a percentage value);

- EAD - creditor's exposure at debtor's default (expressed in absolute value).

In our methodology, the NDP indicator is the equivalent of the product between LGD and EAD in the formula for determining the expected loss occurring if a credit risk gets materialized. This fact is demonstrated in Table no. 1.

Table no. 1 - The calculation of the absolute value of the LGD vs the absolute value of the NDP

\begin{tabular}{|c|c|c|c|}
\hline Components & Indicators & $\begin{array}{l}\text { What it represents/ how } \\
\text { to calculate }\end{array}$ & $\begin{array}{l}\text { How they are } \\
\text { expressed in value }\end{array}$ \\
\hline \multirow{5}{*}{ Absolute value of LGD } & EAD & $\begin{array}{l}\text { creditor's exposure at } \\
\text { debtor's default }\end{array}$ & absolute value \\
\hline & Collateral (C) & $\begin{array}{l}\text { weighted amount of } \\
\text { guarantees }\end{array}$ & absolute value \\
\hline & weight of collateral (iWC) & $\mathrm{C} / \mathrm{EAD}$ & percentage value \\
\hline & LGD & 1-iWC & percentage value \\
\hline & Absolute value of LGD & EAD*LGD & absolute value \\
\hline \multirow{5}{*}{ Absolute value of NDP } & VTP & $\mathrm{VPBC}+\mathrm{VPBD}$ & absolute value \\
\hline & VPBC & $\begin{array}{l}\text { amount that can be } \\
\text { compensated }\end{array}$ & absolute value \\
\hline & Compensation report (CR) & VPBC/VPBD & percentage value \\
\hline & NDP & $1-\mathrm{CR}$ & percentage value \\
\hline & Absolute value of NDP & VTP *NDP & absolute value \\
\hline
\end{tabular}

Source: the authors' own analyses

In calculating the NDP, the following are not taken into account: (i) transactions relevant to public offers and special operations for which the settlement system does not use the resources of the Guarantee Fund if there is a lack of funds in the settlement and (ii) the amounts representing current additional required collateral, seeing that the participant deposited individual additional collateral for this.

The probability of default will be determined on a semi-annual basis, based on the internal rating ascribed to the participant after the manager of the settlement system applies a

${ }^{4}$ https://www.investopedia.com/terms/e/exposure_at_default.asp

DOI: 10.2478/picbe-2020-0088, pp. 925-939, ISSN 2558-9652| Proceedings of the $14^{\text {th }}$ International Conference on Business Excellence 2020 
creditworthiness assessment procedure. The internal rating is determined based on a scoring formula which takes into account both the indicators provided by the legislation on capital adequacy and economic and financial indicators. This rating is recalculated on a semi-annual basis. The decision to update a participant's probability of default will depend on the scoring obtained by entering the new levels of the indicators obtained by it.

The mean value of the net debt positions will be calculated on a monthly basis, by updating the historical observations with those recorded in the previous calendar month.

A methodology to determine the internal rating for each participant, that can be used by the settlement system operator, is presented in "Estimating the credit risk score for non-bank stock exchange intermediaries in the eventuality of changeover to euro currency; Barangă, Laurenţiu Paul, PhD; Panait, Iulian, PhD. Financial Studies; Bucharest Vol. 22, Iss. 4, (2018): table 1; 10$11 ”$.

If the participant has a rating established by a recognized/certified rating agency, that rating will be used in the entity's assessment procedure. Thus, the probability of default of that participant will be determined by taking into account the rating granted by the rating agency with international/European recognition.

b. Contribution to the margin accounts - CMS

It takes into account any potential dynamics of the daily average value of the net debt position of each participant. Its purpose is to assess the potential unexpected loss that could result from the analysis of the historical values of the net basis settlements made for each participant.

To determine the contribution to the margin accounts, the standard deviation of the daily average values of the net debt positions recorded by each participant will be calculated for each month within a time horizon of 12 months. The contribution to the margin account is calculated according to the following formula:

where:

$$
C M A=P D * S D N D P
$$

- $\quad$ CMA - contribution to the margin account (expressed in absolute value);

- $\quad$ PD - probability of default, determined depending on the participant's rating (expressed as a percentage value);

- SDNDP - standard deviation of the net debt position, which takes into account the dynamics of the value of a participant's exposure and is calculated as a standard deviation of the net debt positions recorded by the participant during the last 12 months. This value is updated on a monthly basis, based on the values of the net debt positions recorded by the participant (expressed in absolute value).

The formula for determining the contribution to the margin account also takes into account the level of the unexpected loss in the event that a credit risk gets materialized. To determine it, the standard deviation of the components included in the formula for determining the expected loss was used. Also, due to the fact that the PD is determined on a semi-annual/quarterly basis (depending on the type of indicators included in the analysis of the main components), it was found that the determination of the standard deviation of the value of this indicator is unlikely to be conducted with statistical relevance (at least 30 observations are needed so that, statistically speaking, the methodology may have statistical relevance, and beyond 100 observations it is considered as an optimal database; this requires the existence of values of the PD recorded on a time horizon of several decades). Due to these reasons, the CMA indicator (which is intended to be similar to the unexpected loss relevant to the credit risk) is determined only by taking into account the standard deviation of the NDP indicator. 
Regarding the probability of default, the same rules will be applied as those presented in the section on the Contribution to the Guarantee Fund. The dynamics of the value of the debt exposure of a participant in the settlement system (standard deviation of the net debt positions) will be calculated on a semi-annual basis by updating the historical observations with the ones recorded during the previous calendar month.

Following the semi-annual assessment, if the resulting variable contribution is higher than

PICBE | 934 the previously calculated variable contribution, the settlement system operator will inform the participants about the value of the additional contributions they must pay (by making a margin call). Also, if according to the assessments the resulting variable contribution is lower than the previously calculated variable contribution, the settlement system operator will inform the participants about the amount of money they are allowed to withdraw.

Similarities and dissimilarities between the various categories of collateral provided by the participants in the guarantee system.

The similarities and dissimilarities between the various categories that can be brought to the guarantee system of a settlement system are shown in Table no. 2.

Table no. 2 - Similarities and dissimilarities between the various categories/forms of collateral

\begin{tabular}{|c|c|c|c|c|}
\hline $\begin{array}{l}\text { Item } \\
\text { no. }\end{array}$ & $\begin{array}{l}\text { Categories of } \\
\text { collateral }\end{array}$ & Similarities & Dissimilarities & Observations \\
\hline 1 & $\begin{array}{l}\text { Contribution to } \\
\text { the Guarantee } \\
\text { Fund - CGF }\end{array}$ & $\begin{array}{l}\text { Constitutes collateral } \\
\text { provided by the } \\
\text { participant in the } \\
\text { guarantee system }\end{array}$ & $\begin{array}{l}\text { Takes into } \\
\text { account a certain } \\
\text { net exposure limit }\end{array}$ & $\begin{array}{l}\text { It cannot be withdrawn. It is } \\
\text { permanently maintained for as long as } \\
\text { it has the quality of participant and is } \\
\text { regularly recalculated depending on } \\
\text { the level of the net debt exposure. }\end{array}$ \\
\hline 2 & $\begin{array}{l}\text { Contribution to } \\
\text { the Margin } \\
\text { Account - CMS }\end{array}$ & $\begin{array}{l}\text { Constitutes collateral } \\
\text { provided by the } \\
\text { participant in the } \\
\text { guarantee system }\end{array}$ & $\begin{array}{l}\text { Takes into } \\
\text { account the } \\
\text { atypical evolution } \\
\text { of the factors } \\
\text { considered when } \\
\text { the CGF was } \\
\text { determined }\end{array}$ & $\begin{array}{l}\text { The excess of collateral can be } \\
\text { withdrawn. It is permanently } \\
\text { maintained for as long as it has the } \\
\text { quality of participant and is regularly } \\
\text { recalculated depending on the level of } \\
\text { the net debt exposure. It is the fixed } \\
\text { margin of a participant. }\end{array}$ \\
\hline 3 & $\begin{array}{l}\text { Contributions of } \\
\text { current additional } \\
\text { collateral - VCAC }\end{array}$ & $\begin{array}{l}\text { Constitutes collateral } \\
\text { provided by the } \\
\text { participant in the } \\
\text { guarantee system }\end{array}$ & $\begin{array}{l}\text { Takes into } \\
\text { account } \\
\text { occasional } \\
\text { transgressions of } \\
\text { the net exposure } \\
\text { limit }\end{array}$ & $\begin{array}{l}\text { It can be completely withdrawn after } \\
\text { settling transactions that led to the } \\
\text { need of providing this additional } \\
\text { collateral. It occurs when the VSL is } \\
\text { exceeded by the VNDP. It is the } \\
\text { variable margin of a participant. }\end{array}$ \\
\hline 4 & $\begin{array}{l}\text { Value of the } \\
\text { settlement limit - } \\
\text { VSL }\end{array}$ & $\begin{array}{l}\text { Contributes to the } \\
\text { sustainability of the } \\
\text { guarantee system }\end{array}$ & $\begin{array}{l}\text { Is the main pillar } \\
\text { based on which } \\
\text { all forms of } \\
\text { collateral are } \\
\text { calculated }\end{array}$ & $\begin{array}{l}\text { It is determined on a daily basis by the } \\
\text { settlement system operator. The } \\
\text { dynamics of this indicator is taken into } \\
\text { account regularly when recalculating } \\
\text { the CGF and the CMS. }\end{array}$ \\
\hline
\end{tabular}

2. Multiplication factor - MF.

Source: the authors' own analyses

This factor takes into account the capacity of the risk management operations in the settlement activity to reduce any net debt position of the participant and implicitly leads to a multiplication of the value of provided collateral that can be taken into account in covering that particular net debt position. Thus, using this indicator, the maximum capacity of a participant to cover, with its own permanently provided/brought collateral, the losses resulting from the application of the special transactions of by remaking failed transactions. 
The multiplication factor regarding the capacity of the risk management operations to reduce any debt taken into account the following aspects: the financial capacity of a participant to cover with its own collateral brought in the guarantee system any resulting negative difference between the original failed transaction and the transaction resulting after applying the risk management measures in the settlement activity (special reverse transaction or operation for remaking the original transaction), as well as the volatility of the market, since it could increase the potential negative difference if a participant is unable to honour its obligations.

As a result of what we have presented above, two indicators must be taken into account in determining the multiplication factor, namely: volatility of the stock index in which the security contemplated by the failed transaction is included, and the liquidity of that security. The probability of success of the special reverse transaction or of the operation for remaking the original transaction depends on the liquidity level. The negative price difference (known as the replacement cost) that the good faith participant could experience is covered from the collateral brought in the guarantee system by the defaulting participant.

Determination of the volatility of the stock index - sigma - in which the security contemplated by the failed transaction is included. It will be made based on the historical data, by identifying the highest volatility level of the stock index for a single day or for several days (depending on the time interval during which the settlement is successfully made) during the days corresponding to a few years' period (between 3 and 5 years to be able to detect historical periods with higher volatility, but also to preserve the accuracy of the calculation to the present reality).

The highest determined value will be the volatility taken into account in determining the replacement cost. The volatility will be calculated separately for each stock index on a quarterly basis. For each data series used, from the observations relevant to an entire year, the standard deviation is calculated, weighted by the time factor relevant to the number of days considered in the settlement.

Later, the analysed data series is supplemented by another observation (with another value corresponding to the weighted daily average of the reference prices relevant to that stock index) and the standard deviation is determined, weighted by the time factor relevant to the number of days considered in the settlement. This process is continued until the analysed data series includes all the observations relevant to the intended number of years (between 3 and 5 years) plus another year before these (which is needed in order to calculate de standard deviation for the first day of the analysed time horizon).

Then, the highest volatility value is identified from the obtained results. It will represent the volatility of the stock index considered in determining the replacement cost for the security contemplated by the failed transaction and which, implicitly, needs to be redone.

To determine the supplementary factor - SF, which takes into account issues connected to the liquidity risk attached to the security contemplated by the failed transaction, two aspects are considered, namely:

- the differences between the dynamics of the value of the stock index and the dynamics of the market price of the security within that stock index, which are due to the fact that the liquidity of that security is lower than the median of the liquidity level recorded by all the securities included in that particular stock index.

- the potential error margins due to the different periods based on which which various components/indicators considered in the formula for determining the value of the additional current collateral to be brought by the participant in the settlement system, are determined/recalculated. 
To cover the aspects presented above, we propose a general value of 2 for the additional factor that will result in a doubling of the volatility of the stock index considered in the formula for calculating the value of the current additional collateral to be brought by the participant in the settlement system. Also, depending on the volatility level and on the size of the liquidity indicators taken into account in defining the formula for calculating that particular stock index, the SF could have lower values than the level we propose herein. These lower levels, adapted to the characteristics of the microstructure of the market, which define the securities included in a stock index, will be regularly determined by the operator of that settlement system.

\section{Value of the current additional collateral - VCAC.}

It is the value by which the settlement limit is increased as a result of the participant's depositing the current additional collateral into the margin account. Thus, the increase of the settlement limit can be made due to the fact that the participants deposit individual additional collateral.

The individual additional collateral can be constituted in the form of financial assets with a high liquidity level and a very low credit risk level (money or government securities) and can be used only to complete the settlement of that participant's transactions. This collateral will not be used for settlement unless another participant makes available the money needed for settlement.

The value of the current additional collateral is calculated on a daily basis and equals the difference between the value of the net debt position recorded by a participant and the value of the settlement limit that can be covered by his collateral brought to the guarantee system of that particular settlement system.

Periods of updating the components/indexes included in the formula for calculating the collateral.

The periods of updating the components/indexes included in the formula for determining the collateral value are shown in Table no. 3

Table no. 3 - Periods of updating the components/indexes

\begin{tabular}{|l|l|l|l|}
\hline $\begin{array}{l}\text { Item } \\
\text { no. }\end{array}$ & \multirow{2}{*}{ Component } & Indicator & Frequency of calculation \\
\hline 1 & \multirow{2}{*}{ MF } & Sigma & Daily \\
\cline { 4 - 5 } 2 & & SF & Monthly/Weekly/Daily \\
\hline 3 & \multirow{2}{*}{ CGF } & PD & Semi-annually/Quarterly \\
\cline { 4 - 5 } & & NDP & Monthly/Weekly/Daily \\
\hline 4 & \multirow{2}{*}{ CMS } & PD & Semi-annually/Quarterly \\
\cline { 3 - 4 } 5 & & SDNDP & Monthly/Weekly/Daily \\
\hline 6 & VNDP & & Daily \\
\hline 7 & VSL & & Daily \\
\hline 8 & VCAC & & Daily \\
\hline 9 & & & Source: the authors' own analyses \\
\hline
\end{tabular}

The probability of default (PD) of a participant in the settlement system can be determined only on a semi-annual or quarterly basis, depending on the types of indicators taken into account in the procedure for analysing the main components. If only prudential indicators specified by the legislation on capital adequacy are taken into account, this indicator can be calculated on a quarterly basis; the prudential data is published quarterly by the financial entities.

If, besides prudential indicators, economic-financial indicators are included in the procedure for the analysis of the main components includes, the PD can be determined on a semiannual basis; the accounting data of the financial entities is published on a quarterly basis.

If, in a component, indicators are used that can be calculated for various periods of time, that component will be determined regularly, at the suitable time interval depending on the highest temporal frequency applicable for determining one of the indicators. 
As a result of what is shown above, the CGF and CMS components can be recalculated by the settlement system operator on a semi-annual/quarterly basis. Any abnormal evolution (beyond the limits considered regularly) of the net debt exposure recorded by a participant is detected in the CGSM component.

Regarding the determination of the daily determination of the indicators, please note that this depends on the internal IT systems of the settlement system operators, as well as on their capacity to implement it.

Example of determining the value of current additional collateral that must be brought by the participant in the settlement system.

Starting from the following hypothetical case experienced by a participant, we will try to determine the necessary indicators:

- a mean value of the net debt positions (NDP) of Lei 10,000

- a standard deviation of the daily average values of the net debt positions (SDNDP): Lei 4,545

- the probability of default (PD) assigned to the internal rating ascribed to the participant is $15 \%$.

- a value of the net debt position (VNDP) of Lei 12,000

Also, the volatility of the stock index in which the security is included is $15 \%$.

1. Contributions of the participant in the guarantee system amounting to Lei 2,182:

$R C P=C G F+C M S$

- value of the contribution to the Guarantee Fund:

$C G F=P D * N D P$

$\mathrm{CGF}=15 \% *$ Lei $10,000=$ Lei 1,500 ;

- variation of the contribution to the margin account:

$C M S=P D * S D N D P$

$\mathrm{CMS}=15 \% * 4545$ lei $=$ Lei 681.75

- total value of the contributions to the guarantee system:

$\mathrm{RCP}=\mathrm{CGF}+\mathrm{CMS}=1,500+681.75=$ Lei $2,181.75$

2. The multiplication factor is 3.33.

$M F=100 /($ sigma $* S F)$

- $\quad$ Twice the volatility $=15 \% * 2=30 \%$

- $100 / 0.3=3.33$

3. Considering the above determinations, it follows that the value of the settlement limit is Lei 7,265.23.

$V S L=M F * R C P$

$\mathrm{VSL}=3.33 *$ Lei $2,181.75$

Based on the information shown above, it follows that, to settle all the transactions in a settlement session, the level of the current additional required collateral that must be brought by the participant in the settlement system is Lei 4,734.77

$V C A C=V N D P-V S L$

$\mathrm{VCAC}=$ Lei $12,000-$ Lei 7,266 $=$ Lei 4,734.77

\section{Conclusion}

In this paper, we propose an assessment framework for the risk attached to the replacement cost that can be used by the securities settlement system operators in their daily activity, in order to 
determine the level of the financial capacity of a participant to the settlement system of honouring its payment obligations pertaining to one day of settlement within a very short time, as well as the possible additional collateral contributions. Our proposal includes a structure of indicators that are needed for assessing the risks attached to the clearing and settlement of transactions with securities.

The methodology we have presented takes into account the principles of assessing/quantifying the liquidity and credit risks presented in Regulation (EU) no. 575/2013 on

PICBE | 938 the capital adequacy of credit institutions and investment firms adapted to the rules and customs governing the risk management operations in the settlement of transactions with securities. Also, the principles relevant to the two categories of financial risks presented in Regulation (UE) nr. $575 / 2013$ have been taken into account, because this piece of legislation regulates the management activity regarding the risk of participants in a settlement system (they can be brokers).

The benefits of the methodology for determining the required collateral corresponding to the securities settlement systems, that we have proposed herein, are the following:

- it can be implemented "as is" at a lower complexity level and gradually developed and extended when more (high-quality) data is available;

- it can be easily adapted (calibrated) and applied by a settlement system operator or by another infrastructure entity of the capital market that manages systems of collaterals deposited by the participants;

- $\quad$ since the settlement systems in securities in the EU do not apply an even methodology, the proposed model may contribute to the alignment of the requirements imposed to the participants in the settlement systems;

- the proposed model complements the range of measures intended to prevent and limit fails in the settlement of transactions with financial instruments.

\section{Limitation of the methodology for determining the required collateral.}

The methodology for managing the risk attached to the settlement activity presented herein is based on two aspects: the settlement system uses the net debt position for the settlement of the value of transactions with securities (it makes a net basis settlement for cash) and, at the same time, the settlement system does not guarantee the final settlement of the transactions concluded by its participants. Because of this, the methodology only takes into account one component of the credit risk, i.e. the replacement cost.

\section{References}

Bank for international Settlements \& OICV-IOSCO (2012). Principles for financial market infrastructures.

CESR \& European Central Bank. (2009). Recommendations for securities settlement systems and recommendations for central counterparties in the European Union.

International Monetary Fund. Monetary and Capital Markets Department. (2019). How to Organize Central Securities Depositories in Developing Markets.

European Central Bank. (2011). Settlement fails - Report on Securities Settlement Systems (SSS) measures to ensure timely settlement.

The European Parliament and the Council. Regulation (EU) no. 909/2014 on improving securities settlement in the European Union and on central securities depositories and amending Directives 98/26/EC and 2014/65/EU and Regulation (EU) no 236/2012, as subsequently amended and supplemented.

Depozitarul Central's Code; https://www.roclear.ro/Download?ID=5094\&Lang=en-US. 
Laurențiu Paul Barangă and Iulian Panait (2018). Estimating the credit risk score for nonbank stock exchange intermediaries in the eventuality of changeover to euro currency. Financial Studies; vol. 22, issue 4, 25-40.

Laurențiu Paul Barangă; Local central contraparty; RSF; Volum 4; Issue 6; 2019.

Laurențiu Paul Barangă, Roxana Mihai and Laura Elly Naghi (2019). Determination of the collateral requirements to be deposited by financial entities to the Central counterparty; $6^{\text {th }}$ PICBE $\mid 939$ SWS International Scientific Conference on Social Sciences, Conference Proceeding, volume 6, Issue 1.

https://www.investopedia.com/terms/e/exposure_at_default.asp. 